\title{
Vasodilators and myocardial blood flow by CZT cameras: Make us see further
}

\author{
Teresa Mannarino, MD, ${ }^{\mathrm{a}}$ Valeria Gaudieri, MD, PhD, and Wanda Acampa, MD, \\ $\mathrm{PhD}^{\mathrm{a}, \mathrm{b}}$ \\ a Department of Advanced Biomedical Sciences, University Federico II, Naples, Italy \\ b Institute of Biostructure and Bioimaging, National Council of Research, Naples, Italy
}

Received Sep 1, 2020; accepted Sep 1, 2020

doi: $10.1007 / \mathrm{s} 12350-020-02369-w$

\section{See related article, pp. 113-122}

In nuclear cardiology the pharmacological stressors have been extensively used in all those conditions in which physical stress test is not indicated. The most used medications for stress myocardial perfusion imaging (MPI) are vasodilators, which carry out their role of activating adenosine receptors and consequently increasing myocardial blood flow. ${ }^{1}$ Adenosine activates all four receptor subtypes $\left(\mathrm{A}_{1}, \mathrm{~A}_{2 \mathrm{~A}}, \mathrm{~A}_{2 \mathrm{~B}}\right.$ and $\left.\mathrm{A}_{3}\right) .{ }^{1} \mathrm{~A}_{2} \mathrm{~A}$ receptors are the subtype that mediates the coronary vasodilator effect, whereas the other subtypes are located in different organs and are responsible for the majority of the adverse side effects such as mast cell degranulation, bronchoconstriction $\left(\mathrm{A}_{2 \mathrm{~B}}\right.$ and $\left.\mathrm{A}_{3}\right)$, and negative chronotropic and inotropic effect $\left(A_{1}\right)$. Dipyridamole has the longest history of use among all the vasodilators with consistent data available in the literature referencing its use in MPI. ${ }^{2}$ Dipyridamole acts on all adenosine receptor subtypes and it has a longer half-life as compared to adenosine, but it may lead to undesirable side effects: flushing, headache, dizziness, hypotension, and atrio-ventricular block. Thus, aminophylline may be required $(125-250 \mathrm{mg}$ ) in order to reduce adverse symptoms of prolonged duration. Recently, regadenoson has been introduced in clinical practice as a selective stimulator of $\mathrm{A}_{2} \mathrm{~A}$ receptors, which determine coronary vasodilation limiting the side effects. Regadenoson has several advantages, such as the

Reprint requests: Wanda Acampa, MD, PhD, Department of Advanced Biomedical Sciences, University Federico II, Via Pansini 5, 80131 Naples, Italy; acampa@unina.it

J Nucl Cardiol 2022;29:123-5.

1071-3581/\$34.00

Copyright (C) 2020 American Society of Nuclear Cardiology. easy administration modality (bolus in standardized dose of $0.4 \mathrm{mg}$, regardless of body weight $)^{3}$ and its good tolerability profile in all patients, especially in those affected by chronic obstructive pulmonary disease, which may contraindicate other vasodilators. ${ }^{4}$ It has been demonstrated that regadenoson MPI provides comparable results for detecting reversible defects as compared to a standard adenosine infusion, without serious drug-related side effects. ${ }^{5}$ After a single bolus infusion, hyperemia is maintained significantly longer than with adenosine facilitating radionuclide distribution for MPI studies. Regadenoson has also been compared to dipyridamole in various studies evaluating diagnostic performance of quantitative perfusion and functional findings using both single-photon emission computed tomography (SPECT) and $\mathrm{PET}^{6,7}$ showing an equivalency in the identification of perfusion defects.

In the last decades, cardiac PET using different pharmacologic agents has been used to calculate myocardial blood flow (MBF) and myocardial perfusion reserve (MPR), providing additional diagnostic and prognostic information in different MPI clinical applications. $^{8-10}$ The effects on MBF of different vasodilators by PET have also been evaluated. Koenders et al. ${ }^{11}$ found a regadenoson-induced myocardial creep on dynamic 82-Rubidium $\left({ }^{82} \mathrm{Rb}\right)$ PET MBF quantification, probably due to increasing respiration and lung volume and thereby to the repositioning of the diaphragm and heart after the induction of the stressor. This motion may affect MBF quantification, especially in right coronary artery (RCA) territory. Johnson and Gould ${ }^{12}$ evaluated hemodynamic parameters and MBF comparing dipyridamole and regadenoson hyperemia by cardiac ${ }^{82} \mathrm{Rb}$ PET. They demonstrated that standard infusion of regadenoson achieved approximately $80 \%$ of absolute stress flow and myocardial perfusion reserve obtained with dipyridamole. However, delaying radionuclide injection about $55 \mathrm{~s}$ after the start of the regadenoson 
bolus increases MBF to $90 \%$ of dipyridamole level. Thus, it emerged that from basic pharmacological and physiological principles, the timing of radiotracer injection after the regadenoson bolus affected the degree of observed hyperemia. ${ }^{12}$ On the contrary, in a retrospective observational study, Goudarzi et al. ${ }^{13}$ compared the two vasodilators in patients referred to ${ }^{82} \mathrm{Rb}$ PET/CT and who were matched for clinical profile, coronary risk factors, and baseline hemodynamics. Their results suggested that regadenoson increases absolute MBF at a level similar to the prior standard dipyridamole. Moreover, lack of weight adaptation of the regadenoson dose in clinical practice does not seem to influence the magnitude of flow increase. Recently, the introduction of novel dedicated cadmium-zinc-telluride (CZT) cameras has led to the opportunity to measure MBF also with SPECT imaging. Several studies have shown that quantification of MBF and MPR values assessed by CZT-SPECT imaging are comparable to PET. ${ }^{14,15}$ However, no data are available about the effects on myocardial hyperemia of different vasodilators by CZTSPECT. In the current issue of the Journal, Brama et al. compared retrospectively MBF and MPR values by using CZT-SPECT, using regadenoson in 66 patients and dipyridamole in 162 patients. A subgroup analysis was also performed in a matched patient population $(\mathrm{N}=82)$ at low risk of coronary artery disease (CAD), without prior history of $\mathrm{CAD}$, diabetes, and with normal MPI and left ventricular ejection fraction. All patients were injected with $250-500 \mathrm{MBq}$ stress-rest $99 \mathrm{mTc}$ tetrofosmin. In the overall population, regadenoson and dipyridamole groups were comparable according to clinical characteristics (gender, age, BMI, cardiac risk factors) and hemodynamic parameters (baseline and hyperemic heart rate, baseline, and hyperemic systolic and diastolic blood pressure). Of note, dipyridamole group had a significantly higher percentage of patients with diabetes mellitus. No significant difference in perfusion defect was found between regadenoson and dipyridamole patients at visual analysis and no information about semi-quantitative analysis of perfusion imaging was given in order to analyze defect extension and severity. Rest MBF and MPR values were comparable between the two groups, whereas stress MBF values were significantly higher in regadenoson patients. This result may be affected by the higher number of diabetic patients in the dipyridamole group. In fact, diabetic subjects have lower values of hyperemic $\mathrm{MBF}^{16}$ due to the microvascular dysfunction diabetes-related and this finding seems to be independent from the type of vasodilator used. In the subgroup analysis of matched patients at low risk of CAD, no significant difference was found in stress MBF, rest MBF, and MPR between dipyridamole and regadenoson group, suggesting that differences found in the overall analysis were maybe related to a patient's selection bias. This study for the first time provides interesting data comparing regadenoson and dipyridamole by CZT camera. However, more studies in larger patient population and using standardized parameters (infusion dose and semi-quantitative analysis) are needed to fully understand the optimal use of new CZT cameras. Thus, we need to see further, remembering that robust data on prognostic significance of MBF and MPR measurements obtained by CZT-SPECT imaging, are still lacking. The better understanding of myocardial hyperemia measurements by CZT cameras could be considered as mandatory to optimize the clinical use of MBF and MPR evaluation in all clinical settings. Since the vasodilator agents differ greatly also in terms of cost, infusion duration, and side effect profile, the key diagnostic question for quantification of flow remains the degree of hyperemia. Prospective and randomized trials could be useful for highlighting which pharmacological stress testing is the best for MPI by CZT cameras, with special focus on dynamic acquisitions, which are expected to become a more and more important tool in routine clinical practice.

\section{Disclosures}

Teresa Mannarino, Valeria Gaudieri, and Wanda Acampa declare that they have no conflict of interest.

\section{References}

1. Jacobson KA (2009) Introduction to adenosine receptors as therapeutic targets. Handb Exp Pharmacol 193:1-24

2. Mann A, Williams J (2020) Considerations for stress testing performed in conjunction with myocardial perfusion imaging. J Nucl Med Technol 48:114-121

3. Gaudieri V, Nappi C, Acampa W, Assante R, Zampella E, Magliulo M et al (2017) Assessment of cardiovascular impairment in obese patients: Limitations and troubleshooting of available imaging tools. Rev Esp Med Nucl Imagen Mol 36:247-253

4. Thomas GS, Tammelin BR, Schiffman GL, Marquez R, Rice DL, Milikien D et al (2008) Safety of regadenoson, a selective adenosine A2A agonist, in patients with chronic obstructive pulmonary disease: A randomized, double-blind, placebo-controlled trial (RegCOPD trial). J Nucl Cardiol 15:319-328

5. Iskandrian AE, Bateman TM, Belardinelli L, Blackburn B, Cerqueira MD, Hendel RC et al (2007) Adenosine versus regadenoson comparative evaluation in myocardial perfusion imaging: Results of the ADVANCE phase 3 multicenter international trial. J Nucl Cardiol 14:645-658

6. Assaad M, Berry A, Palanisamy J, Fenner J, Zughaib M (2019) Differential effect of regadenoson versus dipyridamole on heart rate in patients with left bundle branch block: How does it affect the results of pharmacological nuclear stress testing? JRSM Cardiovasc Dis 8:2048004019828257

7. Cullom SJ, Case JA, Courter SA, McGhie AI, Bateman TM (2013) Regadenoson pharmacologic rubidium-82 PET: A comparison of 
quantitative perfusion and function to dipyridamole. J Nucl Cardiol 20:76-83

8. Zampella E, Acampa W, Assante R, Nappi C, Gaudieri V, Mainolfi CG et al (2018) Combined evaluation of regional coronary artery calcium and myocardial perfusion by (82)Rb PET/CT in the identification of obstructive coronary artery disease. Eur $\mathrm{J}$ Nucl Med Mol Imaging 45:521-529

9. Gaudieri V, Acampa W, Rozza F, Nappi C, Zampella E, Assante R et al (2019) Coronary vascular function in patients with resistant hypertension and normal myocardial perfusion: A propensity score analysis. Eur Heart J Cardiovasc Imaging 20:949-958

10. Zampella E, Acampa W, Assante R, Gaudieri V, Nappi C, Mannarino $\mathrm{T}$ et al (2019) Combined evaluation of regional coronary artery calcium and myocardial perfusion by (82)Rb PET/CT in predicting lesion-related outcome. Eur J Nucl Med Mol Imaging. h ttps://doi.org/10.1007/s00259-019-04534-x

11. Koenders SS, van Dijk JD, Jager PL, Ottervanger JP, Slump CH, van Dalen JA (2019) Impact of regadenoson-induced myocardial creep on dynamic Rubidium-82 PET myocardial blood flow quantification. J Nucl Cardiol 26:719-728

12. Johnson NP, Gould KL (2015) Regadenoson versus dipyridamole hyperemia for cardiac PET imaging. JACC Cardiovasc Imaging 8:438-447

13. Goudarzi B, Fukushima K, Bravo P, Merrill J, Bengel FM (2011) Comparison of the myocardial blood flow response to regadenoson and dipyridamole: A quantitative analysis in patients referred for clinical $82 \mathrm{Rb}$ myocardial perfusion PET. Eur J Nucl Med Mol Imaging 38:1908-1916

14. Acampa W, Zampella E, Assante R, Genova A, De Simini G, Mannarino T et al (2020) Quantification of myocardial perfusion reserve by CZT-SPECT: A head to head comparison with $82 \mathrm{Ru}-$ bidium PET imaging. J Nucl Cardiol. https://doi.org/10.1007/ s12350-020-02129-w

15 Agostini D, Roule V, Nganoa C, Roth N, Baavour R, Parienti J-J et al (2018) First validation of myocardial flow reserve assessed by dynamic 99mTc-sestamibi CZT-SPECT camera: Head to head comparison with 15O-water PET and fractional flow reserve in patients with suspected coronary artery disease. The WATERDAY study. Eur J Nucl Med Mol Imaging 45:1079-1090

16 Assante R, Acampa W, Zampella E, Arumugam P, Nappi C, Gaudieri V et al (2017) Coronary atherosclerotic burden vs. coronary vascular function in diabetic and nondiabetic patients with normal myocardial perfusion: A propensity score analysis. Eur J Nucl Med Mol Imaging 44:1129-1135

Publisher's Note Springer Nature remains neutral with regard to jurisdictional claims in published maps and institutional affiliations. 